\title{
A geo-spatial study on spatio-temporal growth of brackish water aquaculture along the coastal areas of West Bengal (India)
}

\author{
Dipanwita Dutta $^{1} \cdot$ Chandra Sekhar Das $^{1} \cdot$ Arnab Kundu $^{2}$
}

Received: 13 January 2016/Accepted: 16 March 2016/Published online: 1 April 2016

(C) Springer International Publishing Switzerland 2016

\begin{abstract}
The present study seeks to identify the landuse changes occurring due to haphazard growth of brackish water fisheries along the coastal areas of West Bengal through remote sensing and GIS techniques. High resolution multi-temporal Google Earth images were used for detecting spatio-temporal changes of two blocks of Contai sub-division located in Midnapore district of West Bengal. Also, the area was surveyed with GPS and the digitized maps were verified using the information collected from the aquaculture farm owners. It is evident from change detection analysis that a significant amount of area under agricultural land has been converted into aquaculture farm and also a large number of pre-existing ponds have been converted into brackish water fisheries. Remote sensing derived statistical information on inland fisheries of Contai II and III blocks reveals that area under brackish water fisheries has increased about 2950 acres within the period 2006 to 2011.
\end{abstract}

Keywords Brackish water aquaculture $\cdot$ Change detection · Remote sensing · GIS

\section{Introduction}

Preservation of environment versus human activity has been a matter of debate over the years. The environmentalists are deeply concerned about sustainable development

Arnab Kundu

arnknd@gmail.com

1 Department of Remote Sensing and GIS, Vidyasagar University, Midnapore, West Bengal, India

2 Centre of Atmosphere, Ocean and Space Studies, University of Allahabad, Allahabad, Uttar Pradesh, India while it's a tendency of human being to exploit the nature as much as possible for fulfillment of their biological and socio-economic demand. As landuse reflects the overall socio-economic characteristics of a region, changes in economic activities may cause massive transformation in landuse/landcover pattern. The past few decades have experienced rapid growth of population in India and as a consequence, transformation of lands occurred to cater food and shelter to the increasing number of population. Coastal ecosystems are characterized by various anthropogenic land uses, among them agriculture and aquaculture are predominant. The coastal areas in some parts of India are having unfavorable condition for rice cultivation as influx of saline water during high tide increases soil salinity. As a result, brackish water aquaculture is being popular over rice cultivation for high returns. It has been reported that the rapid expansion of coastal aquaculture in India is responsible for landscape transformation, such as mangrove deforestation and loss of agricultural land (Vadlapudi 2003; Hein 2000; Hossain et al. 2002; Rajitha et al. 2007). Recent studies revealed that the landuse/landcover along the coastal border of West Bengal is being changing rapidly mainly due to the mushrooming of aquaculture firms (Mitra and Santra 2011; Samanta and Hazra 2012). This trend of land conversion to brackish water aquaculture have been claimed to be major cause of soil salinization in the area. The aquaculture farms are intermittently situated with agricultural lands causing seepage of saltwater through leakage from aquaculture boundary wall, overflow and leaching from sludge pile during rainfall (Mitra and Santra 2011).

Considering the vulnerability of haphazard growth of aquaculture firms, it is necessary to understand and quantify the process of aquaculture related land conversion. Since most of these brackish water fisheries are 
unauthorized it is impossible to acquire information on converted lands from land records and fishery departments. In this perspective, remote sensing is the only way to obtain spatial information through a series of synoptic data for large geographic areas uniformly in time and space, without having the need for exhaustive field surveys (Laba et al. 1997). The sustainable use of the earth's resources requires acquiring of accurate and up-to-date spatial information on land cover and land-cover change. Remote sensing techniques can be used for multi-temporal monitoring, revealing the changes in the land cover and supplying important information on land-cover dynamics (Singh 1989; Barman et al. 2016). The satellite based remote sensing products and modern image processing techniques have proved their usefulness in periodic assessment of the coastal land use and land cover changes and formulating better management system (Klemas 1986; Specter and Gayle 1990; Jana et al. 2016; Emran et al. 2016). Satellite images are not only suitable for visualize the change; also they are valuable source for extracting statistical information related to land use and land cover (LULC) change. Geo-spatial techniques have been used by several researchers engaged in coastal based studies (Williams et al. 2015; Das et al. 2016; Gopinath et al. 2016; Nandi et al. 2016).

The global inland and marine capture fisheries have experienced relatively modest growth over the last half century; however, production from marine capture fisheries has leveled off in recent years while aquaculture has increased rapidly. The freshwater culture and brackish water culture have increased nine fold, six fold, and five fold, respectively, since 1980 (FAO Aqua-Book 2002). India holds a remarkable share in inland fish production of world and the brackish water aquaculture is very common in all coastal states including West Bengal. Being one of the major inland fish producers of country, the state offers vast scope for development of brackish water fisheries. The coastal districts like East Midnapore of West Bengal and areas adjoining Sundarban have unique opportunities of brackish water fish cultivation due to inflow of saline water during high tide. Considering its potential and impressive annual growth, Government of India is also emphasizing on aquaculture development. Brackish water aquaculture in East Midnapore especially in different blocks of Contai has witnessed a remarkable transformation from highly traditional activity to well developed industry. The present study seeks to identify the major landuse changes related to conversion of land for developing aquaculture firms in the Contai-II and Contai-III blocks of East Midnapore district of West Bengal and generating spatio-temporal database for detecting the growth of brackish water aquaculture firms during 2006-2011.

\section{Study area}

The study area is located in East Midnapore district which was a part of erstwhile Midnapore district of West Bengal until 1st January 2002. Lying along the Bay of Bengal to the extreme west of this region, this district falls under Kanthi coastal Plain off the Bay of Bengal. The Study area comprises Contai-III, Contai-II (Deshapran) blocks bounded by the Bhagwanpur-II, Khejuri-II Blocks in the north khejuri-II; Bay of Bengal (Hooghly River) in the east; Contai-I and Bay of Bengal in the south and Patashpur-II and Egra-II Blocks in the west. Geographically, this area is located between $21^{\circ} 42^{\prime} \mathrm{N}$ to $21^{\circ} 56^{\prime} \mathrm{N}$ latitude and $87^{\circ} 36^{\prime} \mathrm{E}$ to $87^{\circ} 54^{\prime} \mathrm{E}$ longitude (Fig. 1). The study area has a coastline of about $14.14 \mathrm{~km}$ with a total geographic area of 33,912 hectares $\left(339.12 \mathrm{~km}^{2}\right)$ consisting of 2 blocks and 16 gram panchayets and 632 villages. The area is characterized by rich inland water resources with good potentiality of aquaculture farming. The topography of the study area can be divided into two parts: (1) quite flat plains on east, west and north, (2) the Kanthi coastal plain on the south. Bounded by the Bay of Bengal in south east sides, the study area is under the formation of fluvio-tidal deposition. This area is characterized by nearly flat surface having average elevation of 5-7 $\mathrm{m}$ above mean sea level and average slope ranging from 0 to 5 degree. As a consequence of flat surface and slow runoff, the areas with relatively low altitude is become frequently congested by tidal water especially during the monsoon season. The Rasulpur river is the main river and Orissa Coast Canal is the major canal of this area. The study area is characterized by a prolonged hot summer (May-September) and short winter (December-February), while October to November is comfortable season with moderate temperature and less humidity. The average annual rainfall of the study area is $1759 \mathrm{~mm}$ (2003). As the study area is formed by recent alluvial deposition, the soils of the study area are mainly medium to fine textured. This area is characterized with over generalized monotonous cropping sequence dominated by paddy. The modification of cropping pattern is difficult to obtain because of poor drainage, salinity and lack of adequate irrigation facilities.

Paddy is the major rain-fed crop and productivity of this crop totally depends upon erratic nature of monsoonal rainfall. Pulses, oilseeds and also a variety of paddy are cultivated in few parts of this area where irrigational water is available during the winter season. Since the productivity of paddy and other crops is very marginal due to saline tidal water, fish farms or brackish water fisheries have become an important source of income. About 3, 32,747 people are living in this coastal region; ten percent among them directly depends on the inland and marine resources for their livelihood. Most of them are basically poor and 




Fig. 1 Location map of the study area

lives exclusively on fishing, either as boat owners or as laborers and sellers of fish and fish products. The saline tidal water inflowing through the unprotected sea dyke and open lands makes it impossible to cultivate any kind of profitable crop in this region. In this circumstance, the brackish water aquaculture acts as the only way for generating direct and indirect employment opportunities and maintaining the livelihood of local people.

\section{Data used and methodology}

High resolution Google based satellite data was used for generating the geo-database for inland water resources and analyzing the quantitative spatio-temporal changes of the study area. The brackish water fisheries and ponds located within the study area were digitized using the Google Earth software and the base maps were prepared for the years 2006, 2009 and 2011. These maps were further verified by field survey using a GPS. Also, direct interviews from the owners of some aquaculture farm helped to collect actual information related to the transformation of lands. The process of acquiring information from satellite images was performed through following steps.

(a) Digitizing and interpreting the Google Satellite Map data.

(b) Measuring the area under aquaculture for different years and quantifying the change.

(c) Verifying the information extracted from Google image using GPS.

The boundary map of Contai-II and Contai-III Blocks were rectified and digitized using the ArcGIS software. In this study, UTM projection system and WGS-84 Datum was applied to the digitized shape files and the projected boundary map was then transformed into $\mathrm{kml}$ file for using it in Google Earth Map. Multi-temporal Google Earth Images were digitized with the help of 'Add Polygon' tool 
of Google Earth Software and the extracted layers of water bodies were stored in . $\mathrm{kml}$ format. These . $\mathrm{kml}$ files were converted into shape files to make them use for further analysis. After generating the database, the number and coverage area under ponds and brackish water aquaculture fisheries were quantified for different years to identify the pace and pattern of spatio-temporal growth of aquaculture farms in the two blocks of Contai region.

\section{Results and discussions}

The present study seeks to identify spatio-temporal growth of aquaculture farms through multi-temporal high resolution Google Earth imageries. While monitoring the mushrooming growth of aquaculture farms, coarse resolution data such as Landsat may not be a good selection as small farms are not clearly detectable from the image. The freely available Google Earth imagery was the only option for extracting such minute features without any cost. One can visually observe the landuse and landcover changes and detect the emergence of new brackish water farms as well as conversion of existing pond into aquaculture farms (Fig. 2). Most of these newly created farms are unauthorized and illegally created by converting agricultural lands. So, neither the fishery department nor Land Revenue offices have such exclusive information regarding the occurrence of such massive change. While conducting the field survey, some owners revealed that they are not willing to authorize land conversion because of complexity in existing laws.

After quantifying the GIS database it was found that Contai II had 12,233 ponds and 5575 brackish water fisheries covering the area of 1040.64 and 1606.39 acres respectively in the year 2006 (Fig. 3). While Contai III block had 13,491 ponds and 3471 brackish water fisheries that covers about 1156.34 and 586.07 acres of lands. It is noteworthy that Contai II has almost three times larger areas under brackish water fisheries than Contai III block (Table 1). The Contai II block situated along the Bay of Bengal with a long open coastal area has more favorable condition for brackish water fisheries. Beside the ponds and brackish water fisheries, canals are also important part of inland fishery of theses blocks.

Present study reveals that there were 11,264 ponds and 9514 brackish water fisheries in Contai II block in the year 2009 (Fig. 4). It covers about 931.77 and 2640.99 acres respectively under pond and brackish water farms. It was found that Contai III block had a total 13,146 numbers of ponds covering the area of 1114.8 acres and 3367 number of brackish water fisheries covering about 826.14 acres area (Table 2).

The areal statistics obtained from the map of 2011 depicts that the number of brackish water fisheries was
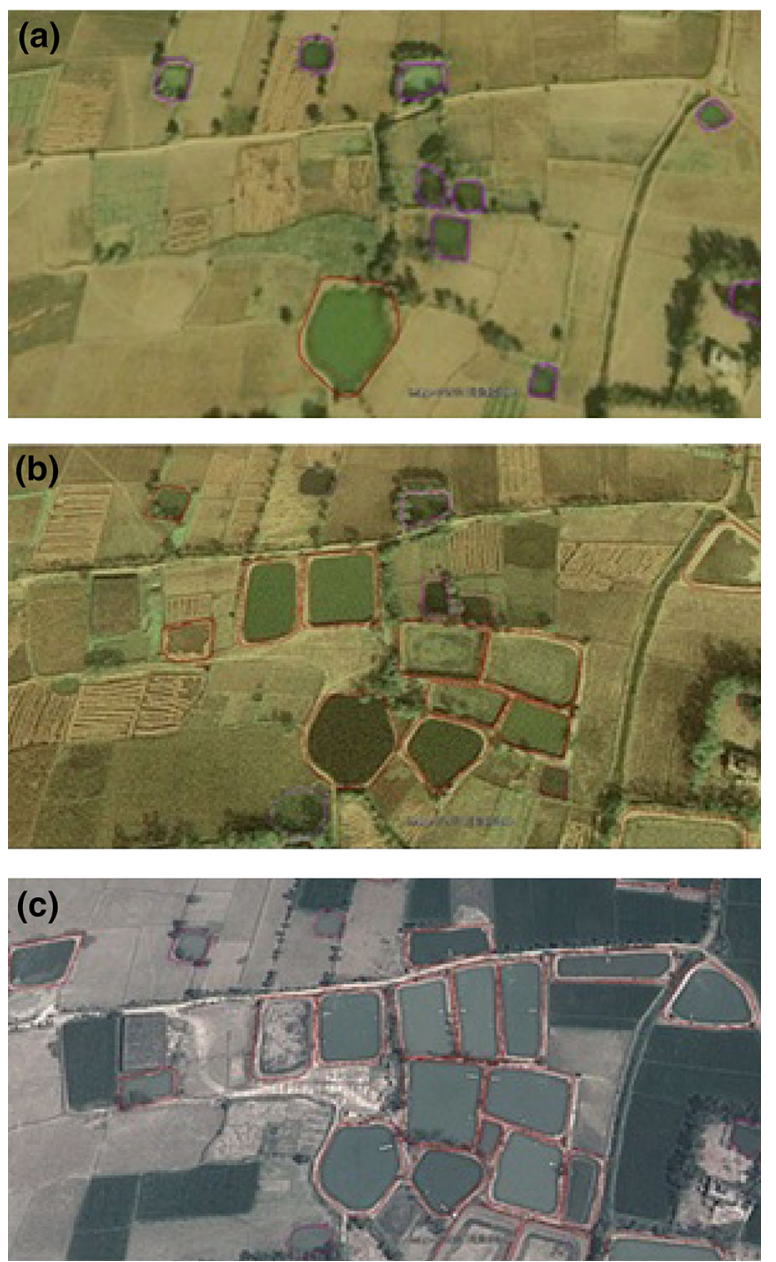

Fig. 2 Google Earth map showing the spatio-temporal changes in water bodies a 2006, b 2009 and c 2011

13,779 in Contai II block covering a total area of 4138.35 acres whereas it was only 4708 in the another block with a total areal coverage of 1004.14 acres (Fig. 5; Table 3). The number of ponds was found 10,850 and 12,731 respectively in the Contai II and III block which covers about 899.45 and 1094.57 acres in those blocks. It has also revealed that most of the brackish water fisheries are confined in Aurai and Amtolia region which has well connecting canal system suitable for brackish water fisheries.

\section{Temporal changes of area under aquaculture farm}

The spatio-temporal change map depicts that two gram panchayet, Aurai and Amtolia of Contai II block experienced major changes during the period 2006-2011 which can be explained by development of new fisheries and conversion of existing ponds into brackish water fisheries (Fig. 6). These areas were visited for field checking and for identifying the reason of such significant transformation of land. The owners of some big aquaculture farm were 
Fig. 3 Spatial distribution of waterbodies in Contai-II and Contai-III blocks (2006)

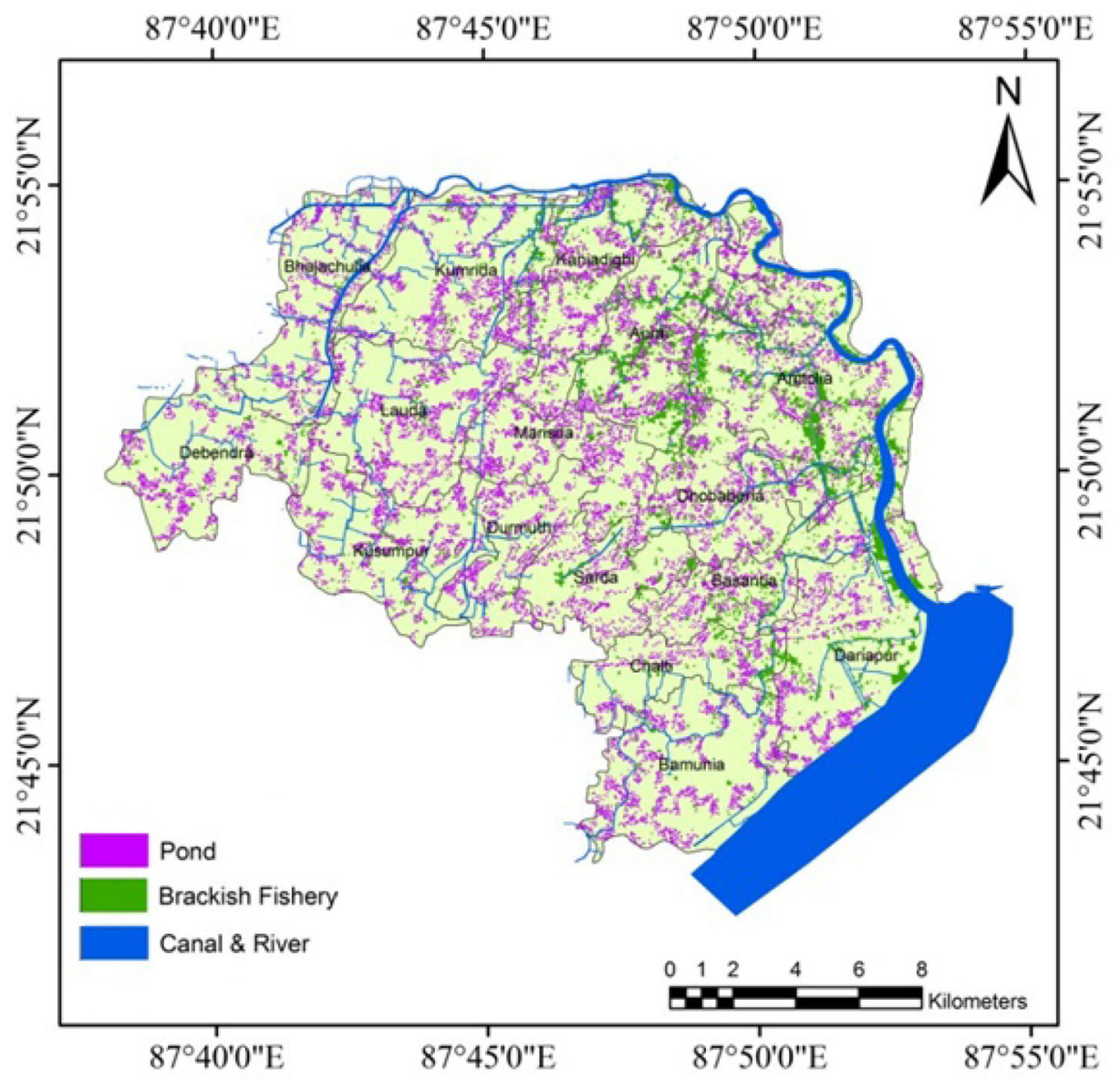

Table 1 Statistics of inland water bodies in Contai-II and Contai-III block in 2006

\begin{tabular}{|c|c|c|c|c|c|c|}
\hline \multirow[t]{2}{*}{ Id } & \multirow[t]{2}{*}{ Name of the block } & \multirow[t]{2}{*}{ Total no. of village } & \multicolumn{2}{|c|}{ Total no. of tanks } & \multicolumn{2}{|c|}{ Total area of tanks (area in acres) } \\
\hline & & & Ponds & Brackish fishery & Ponds & Brackish fishery \\
\hline 1 & Contai-II & 235 & 12,233 & 5575 & 1040.64 & 1606.39 \\
\hline 2 & Contai-III & 388 & 13,491 & 3471 & 1156.34 & 586.07 \\
\hline 3 & Total & 623 & 25,724 & 9046 & 2196.98 & 2192.46 \\
\hline
\end{tabular}

interviewed to collect information related to this abrupt change of land use pattern. We found good agreement between satellite images based spatio-temporal analysis of fisheries and the actual scenario of aquaculture practices over there. All of the gram panchayet within the Contai II block experienced sharp increase in number and area of brackish water fisheries, though the pace of growth rate was not same for all (Fig. 7a). Remote sensing derived statistical information on inland fisheries of the years 2006, 2009 and 2011 reveals an overall increase of areas under brackish water fisheries and decrease of areas under ponds. Brackish water fishery in Contai II block has experienced a massive growth of about 2531.96 acres area in which 141.19 acres are converted from existing ponds and
2390.77 acres area has added as newly created brackish water farm (Table 4; Fig. 8a, b). Most of the new brackish water fisheries of Contai II block were developed during the period 2009-2011. While Contai II block experienced a massive increase in both number of farms and area under brackish water aquaculture, Contai III block has slight different scenario. The study shows that the total area under aquaculture area of Contai III has increased only 418.07 acres within which 356.30 acres are newly created and remaining areas are converted from pre-existing ponds (Table 5; Fig. 9a, b). Although an upward growth is evident in the area under brackish water farm within the period, 2006-2011, the number of brackish water farm developed in the Contai III block was negligible than 
Fig. 4 Spatial distribution of water bodies in Contai-II and Contai-III blocks (2009)

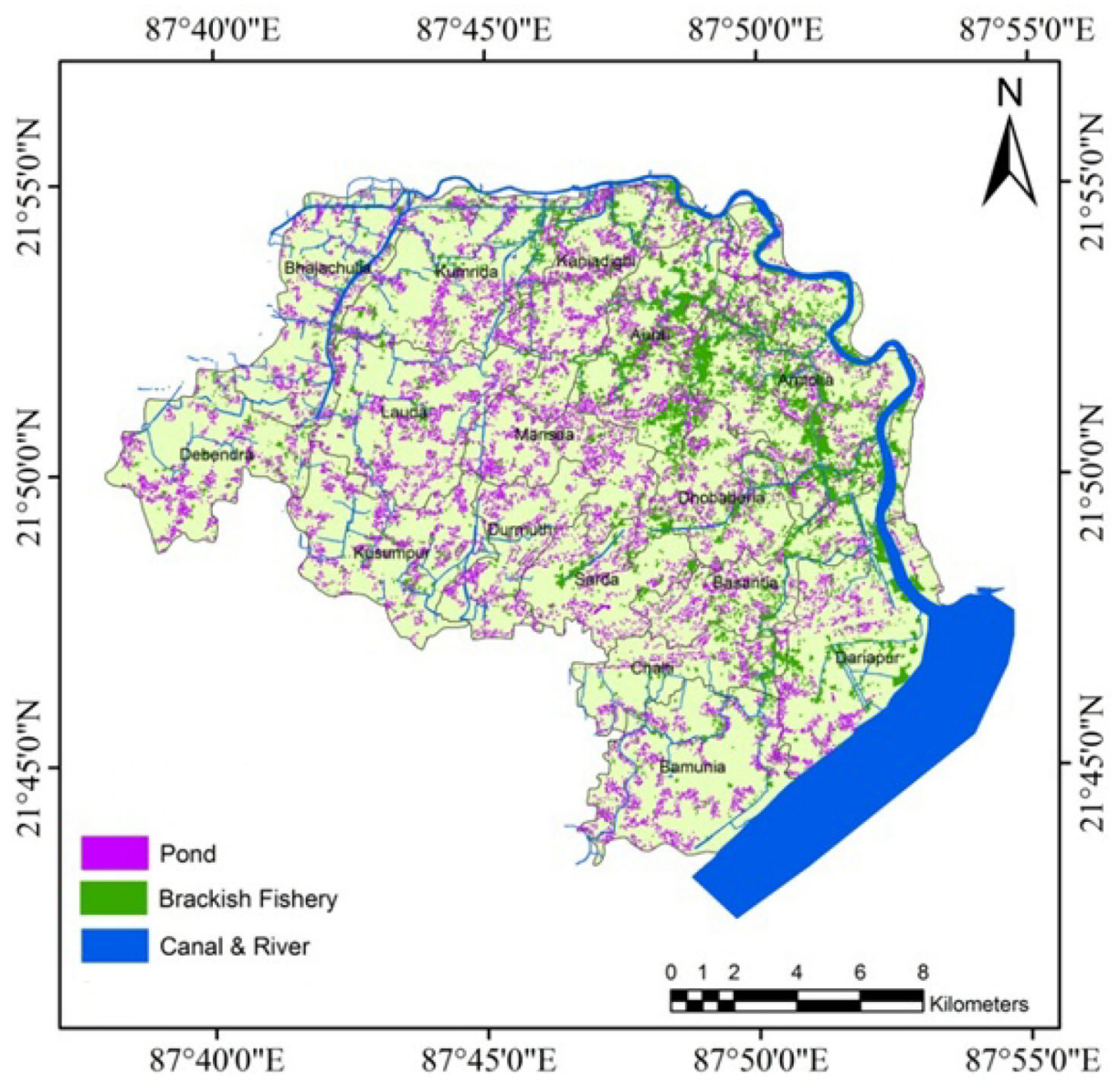

Table 2 Statistics of inland water bodies of Contai-II and Contai-III block in 2009

\begin{tabular}{|c|c|c|c|c|c|c|c|}
\hline \multirow[t]{2}{*}{ Id } & \multirow[t]{2}{*}{ Name of the block } & \multirow[t]{2}{*}{ Total no. of village } & \multirow[t]{2}{*}{ Total no. of mouza } & \multicolumn{2}{|c|}{ Total no. of tanks } & \multicolumn{2}{|c|}{ Total area of tanks (area in acres) } \\
\hline & & & & Ponds & Brackish fishery & Ponds & Brackish fishery \\
\hline 1 & Contai-II & 235 & 169 & 11,264 & 9514 & 931.77 & 2640.99 \\
\hline 2 & Contai-III & 388 & 166 & 13,146 & 3367 & 1114.8 & 826.14 \\
\hline 3 & Total & 623 & 335 & 24,410 & 12,881 & 2046.57 & 3467.13 \\
\hline
\end{tabular}

Contai II block (Fig. 6). Also, the spatial distribution of newly formed aquaculture farm was not equal for all gram panchayet (Fig. 7b).

Kanai-dighi and Lauda gram panchayet had experienced significant growth in brackish water aquaculture during the period 2009-2011. The dispersion in the development of aquaculture farm can be explained by the location of these two blocks. Brackish water aquaculture needs sufficient supply of saline water and good connectivity to sea, the main source of saline water. Brackish water aquaculture is more suitable than sweet water fisheries in the areas where canals or rivers are well connected with sea. Since the Contai block II is situated along the Rasulpur River and most of the gram panchayet have ample supply of saline tidal water through canals, it has been more favorable for development of brackish water aquaculture than the Contai III block.

As Contai II block is attached to the coastal area of Bay of Bengal, the presence of salt is higher in the soil and water of the area. The presence of salt in the stream and ground water decreases the productivity of crops. In spite of the cultivation of green vegetables in some places of the area, the majority of local people have been compelled to involve in the profession of fishing. As a result, the ponds which are not used for domestic purposes, the fallow lands and the agricultural lands of the area are being heavily utilized for fisheries. Although the presence of salt is relatively less in the soil of Contai-III block, but the profit in brackish water fishery has encouraged a number of people to choose the fishery as occupation. Also, rapid growth of 
Fig. 5 Spatial distribution of water bodies in Contai-II and Contai-III blocks (2011)

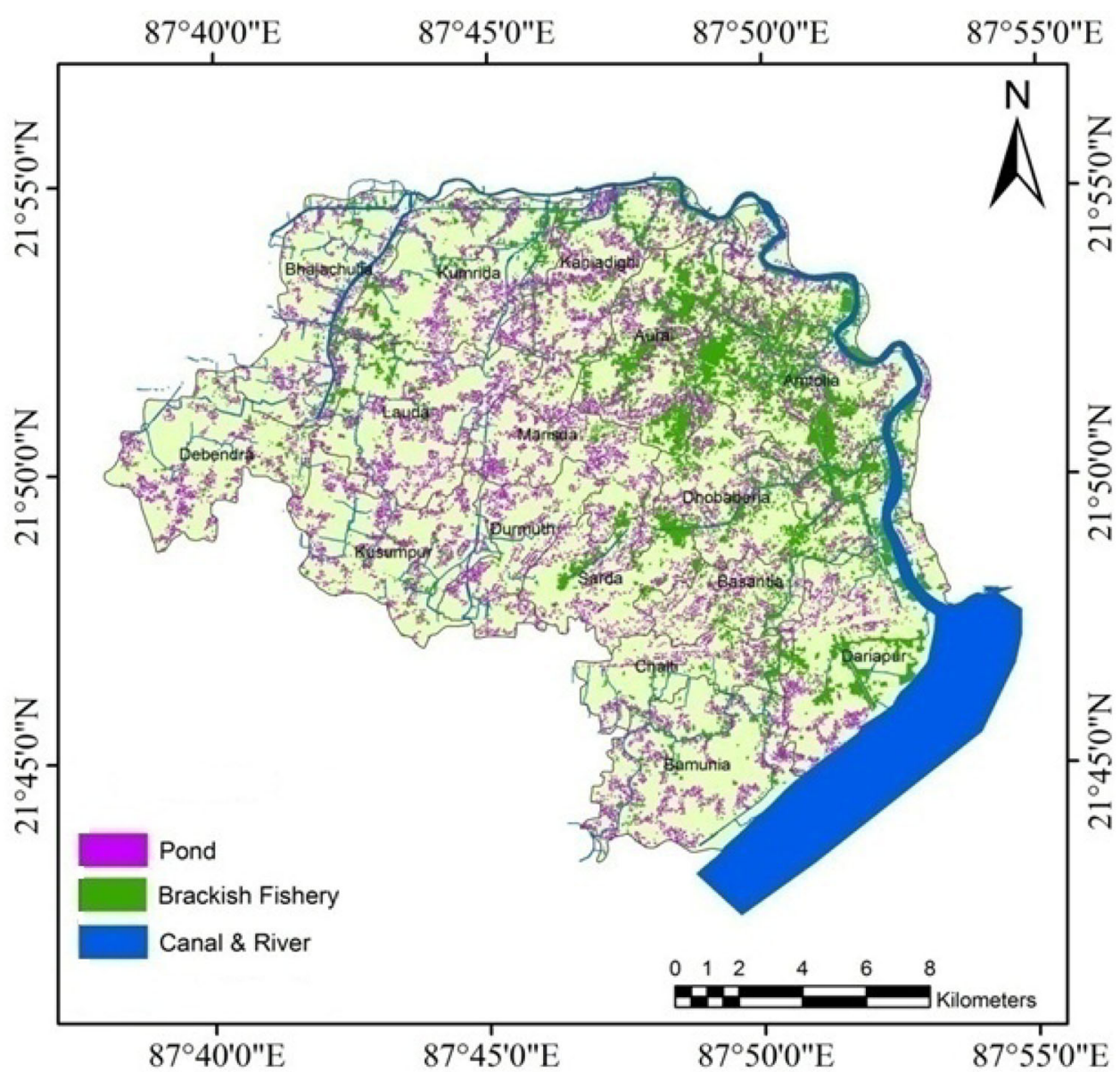

Table 3 Statistics of inland water bodies of Contai-II and Contai-III block in 2011

\begin{tabular}{|c|c|c|c|c|c|c|c|}
\hline \multirow[t]{2}{*}{2011} & \multirow[t]{2}{*}{ Name of the block } & \multirow[t]{2}{*}{ Total no. of village } & \multirow[t]{2}{*}{ Total no. of mouza } & \multicolumn{2}{|c|}{ Total no. of tanks } & \multicolumn{2}{|c|}{ Total area of tanks (area in acres) } \\
\hline & & & & Ponds & Brackish fishery & Ponds & Brackish fishery \\
\hline 1 & Contai-II & 235 & 169 & 10,850 & 13,779 & 899.45 & 4138.35 \\
\hline 2 & Contai-III & 388 & 166 & 12,731 & 4708 & 1094.57 & 1004.14 \\
\hline 3 & Total & 623 & 335 & 23,581 & 18,487 & 1994.02 & 5142.49 \\
\hline
\end{tabular}

population, decreasing profit from agriculture, lack of any other source of income and high profit in brackish water prawn cultivation fuelling the growth of aquaculture farms over the region. The fishermen of this Contai coastal region are earning handsome amount of money by exporting tiger prawn (bagda) and their lifestyle has been changed rapidly.

\section{Conclusions}

With the rapid growth of population and their market demand, spatio-temporal pattern of different types of inland fisheries has been changed in the area. The present study depicts incidence of massive change in aquaculture farming along the coastal areas of Contai within a very short time span. This study has also demonstrated that the high resolution images coupled with GPS based field survey can be very useful for extracting detail information of earth surface and estimating the landuse change related to conversion of land. The study area, Contai II and III blocks experienced rapid increase in brackish water aquaculture farm and conversion of pond and agricultural or fallow land into brackish water fisheries. During the years between 2006 and 2011 about 2950 acres of the study area has converted into brackish water fisheries. Certainly these farms are beneficial for overall economic growth of the area as net profit from tiger prawn is much higher than paddy or other crops. But this mushrooming aquaculture 


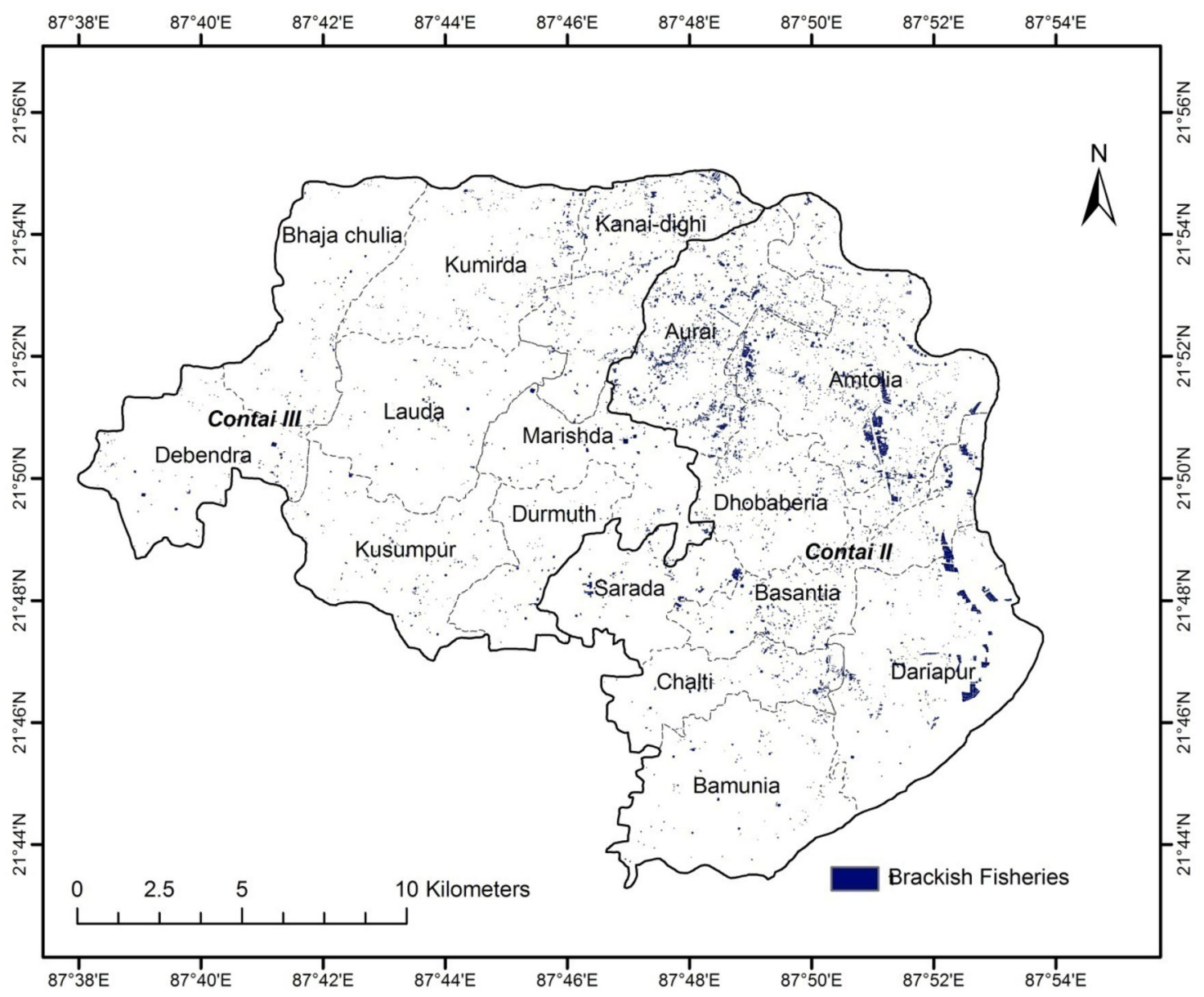

Fig. 6 Brackish water fisheries developed during 2006-2011

(a)

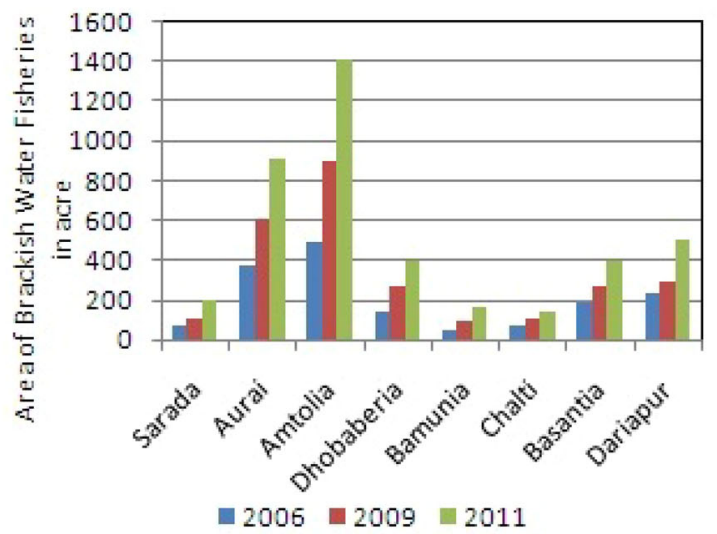

(b)

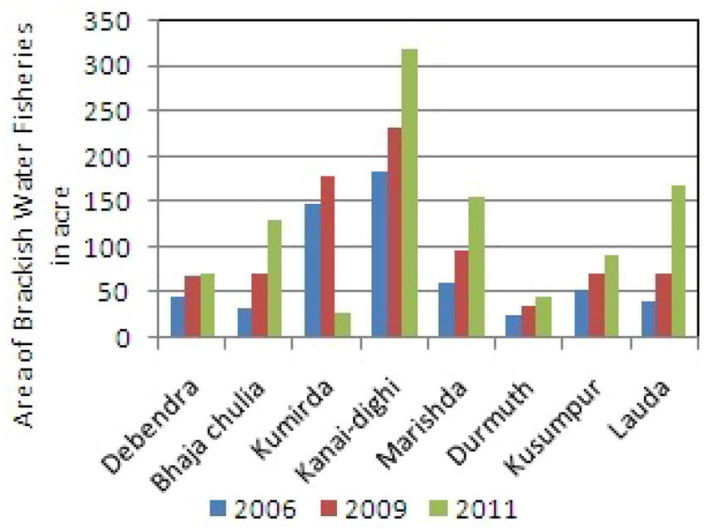

Fig. 7 Growth of brackish water fisheries in different gram panchayet of Contai II (a) and Contai III (b) blocks during 2006-11

farms have long term negative impact on environment. The biodiversity of this area is threatened as different marine fishes being wasted during collection of prawn seedlings along the shorelines. Also, monoculture of tiger prawn making other species of sweet water fishes vulnerable. It is also noteworthy that crop cultivation in the surrounding areas of brackish water fisheries are experiencing decline in productivity due to increasing salinity of soil resulting from 
Table 4 Number and area of brackish water fisheries in Contai-II block (2006-2011)

\begin{tabular}{|c|c|c|c|c|c|c|}
\hline \multirow[t]{2}{*}{ Year } & \multicolumn{3}{|l|}{ No. of brackish fisheries } & \multicolumn{3}{|c|}{ Area under brackish fisheries(in acres) } \\
\hline & Converted from pond & Newly created & Total & Converted from pond & Newly created & Total \\
\hline 2006-2009 & 345 & 140 & 345 & 41.54 & 198.53 & 240.07 \\
\hline 2009-2011 & 415 & 926 & 1341 & 20.23 & 157.77 & 178.00 \\
\hline Total (2006-2011) & 760 & 1066 & 1826 & 61.77 & 356.30 & 418.07 \\
\hline
\end{tabular}

(a)

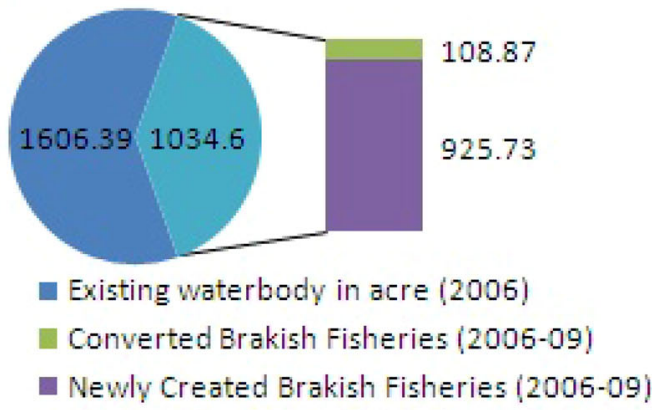

(b)

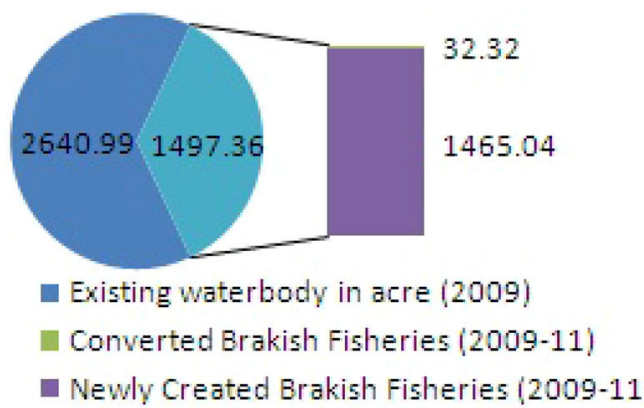

Fig. 8 Distribution and growth of brackish water fisheries in Contai-II block during 2006-2009 (a) and 2009-2011 (b)

Table 5 Number and area of brackish water fisheries in Contai-III block (2006-2011)

\begin{tabular}{|c|c|c|c|c|c|c|}
\hline \multirow[t]{2}{*}{ Year } & \multicolumn{3}{|c|}{ No. of brackish fisheries } & \multicolumn{3}{|c|}{ Area under brackish fisheries (in acres) } \\
\hline & Converted from pond & Newly created & Total & Converted from pond & Newly created & Total \\
\hline 2006-2009 & 969 & 2970 & 3939 & 108.87 & 925.73 & 1034.60 \\
\hline 2009-2011 & 414 & 3851 & 4265 & 32.32 & 1465.04 & 1497.36 \\
\hline Total (2006-2011) & 1383 & 6821 & 8204 & 141.19 & 2390.77 & 2531.96 \\
\hline
\end{tabular}

(a)

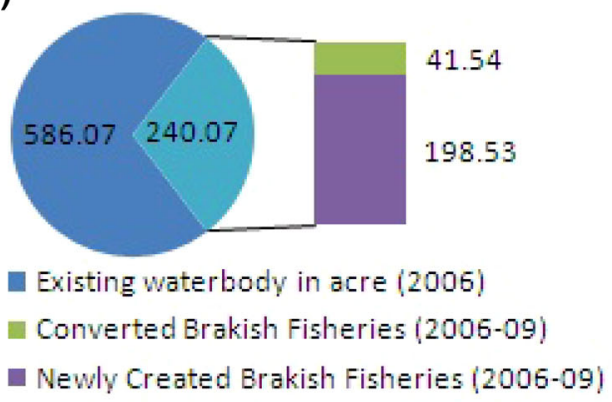

(b)

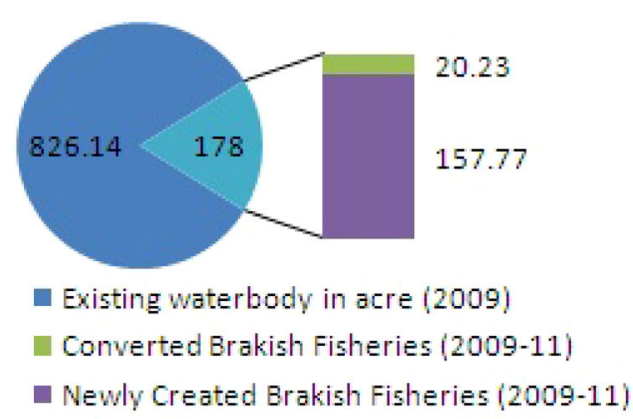

Fig. 9 Distribution and growth of brackish water fisheries in Contai-III block during 2006-2009 (a) and 2009-2011 (b)

seepage and overflow of brackish water during rainy season. Inspite of having many laws and regulations, the agricultural farmers are facing trouble to eradicate this problem. Owing to the market value of tiger prawn, the future of brackish water aquaculture seems bright but the government should be aware of all possible threats from this haphazard growth of aquaculture farms otherwise the coastal ecosystem would suffer enormously.

Acknowledgments The authors are indebted to Vidyasagar University, West Bengal (India) for providing necessary support to successfully complete the study. Acknowledgement also goes to Google for providing satellite imageries used in this study. 


\section{References}

Barman NK, Chatterjee S, Paul AK (2016) Estimate the coastal vulnerability in the Balasore Coast of India: a statistical approach. Model Earth Syst Environ 2:20. doi:10.1007/s40808015-0074-6

Das Y, Mohanty UC, Jain I (2016) Development of tropical cyclone wind field for simulation of storm surge/sea surface height using numerical ocean model. Model Earth Syst Environ 2:13. doi:10. 1007/s40808-015-0067-5

Emran A, Rob MA, Kabir MH, Islam MN (2016) Modeling spatiotemporal shoreline and areal dynamics of coastal island using geospatial technique. Model Earth Syst Environ 2:4. doi:10. 1007/s40808-015-0060-z

FAO Aqua-Book (2002) Shrimp aquaculture-global and Indian scenario. Available online at: http://aquaculture.tn.nic.in

Gopinath S, Srinivasamoorthy K, Saravanan K, Suma CS, Prakash R, Senthilnathan D, Chandrasekaran N, Srinivas Y, Sarma VS (2016) Modeling saline water intrusion in Nagapattinam coastal aquifers, Tamilnadu, India. Model Earth Syst Environ 2:2. doi:10.1007/s40808-015-0058-6

Hein L (2000) Impact of shrimp farming on mangroves along east coast of India. Unasylva 51:48-54

Hossain MZ, Muttitanon W, Tripathi NK, Phillips M (2002) Monitoring shrimp farming development from the space: a RS and GIS approach in Kandleru creek area, Andhra Pradesh, India. Map Asia Conference, GIS Development Pvt. Ltd., Noida

Jana A, Maiti S, Biswas A (2016) A seasonal change monitoring and mapping of coastal vegetation types along Midnapur-Balasore Coast, Bay of Bengal using multi-temporal landsat data. Model Earth Syst Environ 2:7. doi:10.1007/s40808-015-0062-x
Klemas V (1986) Remote sensing of coastal resources in developing countries. In: Proceedings conference on remote sensing and its impact on developing countries, pontifical academy of sciences. Rome, pp 16-21

Laba M, Smith SD, Degloria SD (1997) Landsat-based land cover mapping in the lower Yuna River watershed in the Dominican Republic. Int J Remote Sens 18:3011-3025

Mitra R, Santra SC (2011) Influence of Brackish water aquaculture on soil salinisation. Int J Res Chem Environ 1:166-168

Nandi S, Ghosh M, Kundu A, Dutta D, Baksi M (2016) Shoreline shifting and its prediction using remote sensing and GIS techniques: a case study of Sagar Island, West Bengal (India). J Coast Conserv 20:61-80

Rajitha K, Mukherjee CK, Vinu Chandran R (2007) Applications of remote sensing and GIS for sustainable management of shrimp culture in India. Aquac Eng 36:1-17

Samanta K, Hazra S (2012) Landuse/Landcover change study of Jharkhali Island Sundarbans, West Bengal using Remote Sensing and GIS. Int J Geomat Geosci 3:299-306

Singh A (1989) Digital change detection techniques using remotely sensed data. Int J Remote Sens 10:989-1003

Specter C, Gayle D (1990) Managing technology transfer for coastal zone development: Caribbean experts identify major issues. Int $\mathbf{J}$ Remote Sens 11:1729-1740

Vadlapudi S (2003) Identification and quantification of changes in mangrove forest using remote sensing-a case study near Kakinada Bay, Andhra Pradesh, India. Map India Conference

Williams JJ, Esteves LS, Rochford LA (2015) Modelling storm responses on a high-energy coastline with XBeach. Model Earth Syst Environ 1:3. doi:10.1007/s40808-015-0003-8 